\title{
Papers
}

\section{Mortality and morbidity in gastro-oesophageal cancer surgery: initial results of ASCOT multicentre prospective cohort study}

Peter McCulloch, Jeremy Ward, Paris P Tekkis for the ASCOT group of surgeons, on behalf of the British Oesophago-Gastric Cancer Group

\begin{abstract}
Objective To evaluate the effect of comorbidity and other risk factors on postoperative mortality and morbidity in patients undergoing major oesophageal and gastric surgery.

Design Multicentre cohort study with data on postoperative mortality and morbidity in hospital.

Data source and methods The ASCOT prospective database, comprising 2087 patients with newly diagnosed oesophageal and gastric cancer in 24 hospitals in England and Wales between 1 January 1999 and 31 December 2002. Multivariate logistic regression analysis was used to model the risk of death and postoperative complications.

Results 955 patients underwent oesophagectomy or gastrectomy. Of these, $253(27 \%)$ were graded ASA III or IV, and $187(20 \%)$ had a high physiological POSSUM score $(\geq 20)$. Operative mortality was 12\% (111/955). Physiological POSSUM score, surgeon's assessment, type of operation, hospital case volume, and tumour stage independently predicted operative mortality. Medical complications were associated with higher physiological POSSUM scores and ASA grade, oesophagectomy or total gastrectomy, thoracotomy, and radical nodal dissection. Stage and additional organ resection predicted surgical (technical) complications.

Conclusions Many patients undergoing surgery for

gastro-oesophageal cancer have major comorbid disease, which strongly influences their risk of postoperative death. Technical complications do not seem to be influenced by preoperative factors but reflect the extent of surgery and perhaps surgical judgment. Detailed prospective multicentre cooperative audit, with appropriate risk adjustment, is fundamental in the evaluation of cancer care and must be properly resourced.
\end{abstract}

\section{Introduction}

Oesophageal and gastric cancer are common diseases that pose considerable challenges to surgeons. Most patients present with advanced disease, and curative surgery requires considerable resources in the operating theatre and in critical care. Published data show large variations in practice and outcome from surgical treatment. ${ }^{1-3}$ Both the optimal surgical techniques and the role of adjuvant therapy remain controversial because randomised trials have failed to resolve important questions or have not yet been performed. The applicability of data from trials to routine practice in gastro-oesophageal cancer surgery is difficult to determine because of the lack of reliable information about patients and outcomes in routine practice. This information gap obstructs the formulation of hypotheses for randomised trials and frustrates efforts to improve standards of treatment. We examined the factors associated with postoperative morbidity and mortality after oesophageal and gastric cancer resection.

\section{Methods}

\section{Data source}

The ASCOT (Assessment of Stomach and Oesophageal Cancer Outcomes from Treatment) database was developed in 1998 by the British Oesophagogastric Cancer Group to provide comprehensive and accurate data on stage, comorbidity, and outcome for cases of oesophageal or gastric cancer. ${ }^{4}$ The dataset comprises 54 data fields divided into sections dealing with demographic data, preoperative assessment, operative details, postoperative course, and pathology. From 1 January 1999 to 31 December 2002, 32 hospitals in England and Wales (about 10\% of all acute trusts doing major cancer surgery) registered with ASCOT on a voluntary basis. Members agreed to enter all details of all patients with gastric or oesophageal cancer referred to them, whether patients underwent resection or not, but relied on their own resources to do this.

\section{Inclusion and exclusion criteria}

In this study of surgical outcomes, we included data on patients undergoing resectional surgery for oesophageal and gastric cancer. We excluded patients who underwent non-surgical treatment (palliative chemotherapy, radiotherapy, endoscopic stenting), patients who underwent surgery without resection (palliative gastrojejunostomy, laparotomy only), and patients whose outcome was not recorded.

\section{End points and risk factors}

The primary outcome was mortality in hospital after resection of gastric or oesophageal cancer, defined as any death during the admission when the operation was performed. This was more reliably quantified than 30 day mortality. The secondary end point was morbidity in hospital. We performed separate analyses of complications apparently related to surgical technique (for instance, anastomotic leakage, fistula, abscess, haemorrhage) and other "medical" complications. The risk factors studied included age, sex, comorbid status, tumour site and stage, surgical approach, and annual case volume (defined as the number of oesophageal and gastric resections undertaken in each unit per year and categorised into three groups; see table 5). We classified tumour site as oesophageal, gastric, or junctional. Data on preoperative health status were collected by using the physiological part of the POSSUM (physiological and operative severity score for the enumeration of mortality and morbidity) 


\begin{tabular}{|c|c|c|c|}
\hline & Gastric & Oesophageal & Junctional \\
\hline No (\%) of cases & $502(53)$ & $229(24)$ & $207(22)$ \\
\hline Mean age (range) $\dagger$ & $70.1(28.6-95.7)$ & $64.9(38.9-85.5)$ & $66.4(33.6-89.1)$ \\
\hline No $(\%)$ of men & $323(64)$ & $168(73)$ & $162(78)$ \\
\hline Median (IQR) length of stay§ (days) & $13(14)$ & $17(15)$ & $15(19)$ \\
\hline
\end{tabular}

*17 (2\%) cases were not classified by anatomical site.

tAnalysis of variance $F_{2873}=21.056, P=0.001$.

$\ddagger \chi^{2}=15.326,2 \mathrm{df}, \mathrm{P}=0.001$.

§Kruskal Wallis test $=18.919,2 \mathrm{df}, \mathrm{P}=0.001$.

score ${ }^{5}$ the ECOG (Eastern Cooperative Oncology Group) performance status, ${ }^{6}$ ASA (American Society of Anesthesiology) grade, ${ }^{7}$ and a surgeon's simple assessment score (see table 3).

\section{Statistical analysis}

Continuous risk factors were grouped into subcategories of increasing operative risk. We used a multilevel logistic regression analysis with backwards stepwise variable selection to identify independent risk factors for operative mortality and morbidity. The standard errors of the model estimates were adjusted for the clustering of patients within hospitals. To maximise the information extracted from the predictor variables, we used a median imputation technique to substitute for incomplete data. ${ }^{8}$

Model validation -The adjusted odds ratios were based on the multivariate analysis of the cases submitted during the first three years of the study $(n=773)$. The model was then tested on the data from the final year of the study $(n=222)$. Model performance was evaluated by the area under the receiver operating characteristic (ROC) curve and the Hosmer Lemeshow test. $^{8}$

Data validation-The ASCOT data were internally validated by requesting duplicate information from the information technology, pathology, and theatre departments of participating hospitals. To test for bias from incomplete reporting, we compared the case volume and operative mortality for oesophageal and gastric resections reported to the ASCOT database with data from the hospital episode statistics (HES), obtained independently for 12 participating units for 1999-2000.

Statistical software-We used STATA version 6.0 software (STATA Corporation, College Station, TX), SPSS version 11 for Windows (SPSS, Chicago, IL), and MLwiN version 1.2 (University of London) in the analysis of results.

\section{Results}

A total of 2087 cases were submitted by 26 hospitals. Six hospitals registered with ASCOT did not contribute any cases. The median number of cases submitted per unit was 34 (range 1-344). We excluded from this analysis 836 patients who underwent non-surgical treatment, 255 patients who underwent non-resectional surgery or palliative stenting, and 41 patients whose outcome was not recorded. A total of 669 patients $(67.2 \%)$ had complete data for the risk factors included in the multivariate analysis.

\section{Surgical treatment}

In 23 hospitals 1251/2087 patients (60\%) underwent surgical treatment and $955(46 \%)$ underwent tumour resection. Three hospitals submitted data but had no patients undergoing resection. Demographic details for patients undergoing resection are shown in table 1 . Operative volume ranged between 2 and 39 cases a year. Nine hospitals performed 10 or fewer resections a year and three hospitals performed more than 30 oesophagogastric resections a year. Of the patients, 590 underwent gastric resection (resection rate 54\%), 365 underwent oesophageal resection (resection rate for oesophageal or junctional cancers 37\%), and 255 underwent non-resectional palliative or exploratory procedures. Only $62(6 \%)$ resections were considered palliative in intent (table 2). There were 254 total gastrectomies, 262 distal gastrectomies, and 365 oesophagectomies. The chest was opened in 337 procedures. Overall, 232 (64\%) of oesophagectomies incorporated a 2-field lymphadenectomy, and 40\% of gastrectomies had "D2" lymphadenectomy. Additional organ resection was performed in 224 patients $(23 \%)$.

\section{Preoperative fitness assessment}

Most patients undergoing resection had unrelated systemic disease, and in many this was severe enough to compromise survival from major surgery. The median "physiological" POSSUM score was 17 (range 12-56, $\mathrm{n}=757), 187(20 \%)$ patients had a score of over 20, $253(27 \%)$ patients were ASA grade III or IV, and $164(14 \%)$ had an ECOG score of $\geq 2: 1.9 \%$ were classified

Table 2 Management profiles of patients undergoing gastric and oesophageal resection for cancer. Figures are numbers (percentages) of patients

\begin{tabular}{|c|c|c|}
\hline & Gastrectomy & Oesophagectomy \\
\hline \multicolumn{3}{|l|}{ Procedure: } \\
\hline Total & 254 (43.1) & NA \\
\hline Distal & $262(44.4)$ & NA \\
\hline Proximal & $34(5.8)$ & NA \\
\hline Completion & $7(1.2)$ & NA \\
\hline Ivor-Lewis & NA & $245(67.1)$ \\
\hline Thoracoabdominal & NA & $25(6.8)$ \\
\hline Transthoracic & NA & $38(10.4)$ \\
\hline Three stage & NA & $29(7.9)$ \\
\hline Other & $33(5.6)$ & $28(7.7)$ \\
\hline \multicolumn{3}{|l|}{ Operative intent: } \\
\hline Curative & $538(91.2)$ & $355(97.3)$ \\
\hline Palliative & $52(8.8)$ & $10(2.7)$ \\
\hline Additional organ resection & $158(26.8)$ & $66(18.1)$ \\
\hline \multicolumn{3}{|l|}{ Lymphadenectomy: } \\
\hline Limited $\left(\mathrm{D}_{1}\right)$ & $289(49.0)$ & NA \\
\hline Extended $\left(\mathrm{D}_{2} / \mathrm{D}_{2+}\right)$ & $238(40.3)$ & NA \\
\hline$\leq 1$-field or less & NA & $109(29.9)$ \\
\hline 2-field & NA & $232(63.6)$ \\
\hline Unclear & $63(10.7)$ & $24(6.6)$ \\
\hline \multicolumn{3}{|l|}{ Staging: } \\
\hline Stage I & $149(25.3)$ & $81(22.2)$ \\
\hline Stage II & $96(16.3)$ & $57(15.6)$ \\
\hline Stage III & $239(40.5)$ & $193(52.9)$ \\
\hline Stage IV & $69(11.7)$ & $22(6.0)$ \\
\hline Unknown & $37(6.3)$ & $12(3.3)$ \\
\hline \multicolumn{3}{|l|}{ Radiochemotherapy: } \\
\hline Neoadjuvant & $17(2.9)$ & $96(26.3)$ \\
\hline Adjuvant & $5(0.8)$ & $2(0.5)$ \\
\hline Total & 590 & 365 \\
\hline
\end{tabular}

$\mathrm{NA}=$ not applicable. 
Table 3 Summary of comorbidity scores for 955 patients undergoing oesophageal or gastric resection

\begin{tabular}{|c|c|}
\hline & № (\%) \\
\hline \multicolumn{2}{|c|}{ ECOG performance status: } \\
\hline 0 & $342(35.8)$ \\
\hline 1 & $385(40.3)$ \\
\hline 2 & $122(12.8)$ \\
\hline 3 & $11(1.2)$ \\
\hline 4 & $1(0.1)$ \\
\hline Missing & $94(9.8)$ \\
\hline \multicolumn{2}{|c|}{ ASA grading: } \\
\hline 1 & $166(17.4)$ \\
\hline II & $491(51.4)$ \\
\hline III & $242(25.3)$ \\
\hline IV & $11(1.2)$ \\
\hline Missing & $45(4.7)$ \\
\hline \multicolumn{2}{|c|}{ Surgeon's assessment*: } \\
\hline 1 & $548(57.4)$ \\
\hline 2 & $251(26.3)$ \\
\hline 3 & $18(1.9)$ \\
\hline Missing & $138(14.5)$ \\
\hline \multicolumn{2}{|c|}{ POSSUM physiological score: } \\
\hline $11-14$ & $201(21.0)$ \\
\hline $15-20$ & $369(38.6)$ \\
\hline $20-30$ & $162(17.0)$ \\
\hline$>30$ & $25(2.6)$ \\
\hline Missing & $198(20.7)$ \\
\hline
\end{tabular}

ECOG=Eastern Cooperative Oncology Group performance status; ASA=American Society of Anesthesiology grading system; POSSUM=physiological and operative severity score for enumeration of mortality and morbidity, physiological part of this scores preoperative fitness. (In all cases higher score or grade indicates worse preoperative health.)

*Grades: 1=patient considered fit for surgery; 2=patient potentially fit for major resection, but significant comorbidity problems identified; $3=$ serious comorbidity problems identified that present considerable risk to survival in postoperative period.

by the surgeon as either severely compromised or unfit for any elective surgery (table 3$)$. Over half $(145,57 \%)$ of the patients who received non-resectional treatment were rejected on fitness grounds.

\section{Postoperative adverse events}

The overall mortality from resection was 111/955 (12\%). Mortality was 8\% (13/166) in ASA grade I patients compared with $9 \%(44 / 491)$ in grade II, $18 \%(44 / 242)$ for grade III, and 27\% (3/11) in grade IV. Among 590 patients undergoing gastric resection, $254(43 \%)$ developed at least one complication. The commonest problems were respiratory infection or failure (20\%) and cardiac failure, arrhythmia, or ischaemia (11\%). Ten percent of patients needed a second operation: 34 patients $(6 \%)$ had an anastomotic or other enteric leak (table 4).

Fifty patients (14\%) undergoing oesophageal resection died in hospital, and $219(60 \%)$ had at least one complication. Technical or surgical complications affected $72(20 \%)$ patients; 148 $(41 \%)$ had respiratory and 57 (16\%) had cardiac complications (table 4).

\section{Analysis of prognostic factors}

Multivariate analysis showed significant associations of mortality in hospital with both physiological POSSUM score and the surgeons' assessment but not with ASA grade or ECOG score (table 5). Tumour stage and type of operation were also significant predictors; patients undergoing partial gastrectomy were at significantly less risk than others. Using the multivariate model, we observed a $51 \%$ reduction in the risk of operative mortality for those hospitals with over 20 resections a year compared with hospitals with fewer than 10 a year. For postoperative complications sex, type of operation (both the type of resection and the approach), physiological POSSUM score, and ASA grade were predictive, but not patient's age. Additional organ resection and stage IV disease were independent predictors for surgical complications, while radical node dissection gave an odds ratio of 1.44 and nearly reached significance. Physiological POSSUM score, ASA grade, surgical approach, extent of node dissection, and type of operation all independently predicted medical complications (table 5). The multivariate models developed for operative mortality and morbidity showed good predictive value when we applied them to the data from the final year of the study (table 6).

\section{Comparison of ASCOT and hospital episode statistics (HES)}

The ASCOT database recorded 199 fewer procedures than were listed in the hospital episode statistics $(n=590)$ for the same number of hospitals $(n=12)$. The recorded group operative mortalities, however, were similar $\left(12.5 \% v 12.7 \%, \chi^{2}=0.007\right.$, $\mathrm{P}=0.934)$. Similar mortality results were recorded for both gastrectomies and oesophagectomies (gastrectomy: 9.0\% $v 11.1 \%$, $\chi^{2}=0.685, \quad \mathrm{P}=0.408 ; \quad$ oesophagectomy: $18.5 \%$ v $14.5 \%$, $\chi^{2}=1.111, \mathrm{P}=0.292$ ). No significant correlation was present for individual unit mortalities in hospital (Pearson correlation $=0.212, \mathrm{P}=0.508$ ), although results were similar for the group of hospitals $(\mathrm{n}=3)$ with case volumes of fewer than 10 cases a year $\left(13.0\right.$ ข $\left.9.2 \%, \chi^{2}=0.286, \mathrm{P}=0.593\right)$. For three units there was gross year on year discrepancy within the data from the hospital episode statistics, and for another three the number of cases reported to ASCOT exceeded those reported to hospital episode statistics.

\section{Discussion}

In Britain, surgical outcomes are currently under unprecedented public scrutiny. Because the information routinely collected by the NHS is completely inadequate for reliable risk adjusted comparisons, most British surgeons have neither accurate information about their own results nor any grasp of how these compare with their peers. For gastro-oesophageal cancer, controversial recommendations about techniques, operative

Table 4 Postoperative complications in patients undergoing oesophageal or gastric resection for cancer. Figures are numbers (percentages) of patients

\begin{tabular}{lccc} 
Complication & Gastric $(\mathbf{n}=\mathbf{5 9 0})$ & Oesophageal $(\mathbf{n}=\mathbf{3 6 5})$ & P value \\
\hline Surgical complications: & & & \\
\hline Anastomotic leak & $19(3.2)$ & $20(5.5)$ & 0.096 \\
\hline Leak elsewhere & $15(2.5)$ & $17(4.7)$ & 0.096 \\
\hline Abscess formation & $18(3.1)$ & $4(1.1)$ & 0.050 \\
\hline Peritonitis & $5(0.8)$ & $1(0.3)$ & 0.261 \\
\hline Ileus & $9(1.5)$ & $2(0.5)$ & 0.143 \\
\hline Wound infection & $21(3.6)$ & $16(4.4)$ & 0.316 \\
\hline Burst abdomen & $1(0.2)$ & $2(0.5)$ & 0.326 \\
\hline Intraluminal bleed & $12(2.0)$ & $1(0.3)$ & 0.313 \\
\hline Extraluminal bleed & $8(1.4)$ & $5(1.4)$ & 0.313 \\
\hline Pancreatic fistula & $7(1.7)$ & $0(0)$ & 0.048 \\
\hline Other & $59(10.0)$ & $27(7.4)$ & 0.172 \\
\hline Required secondary surgery & $60(10.2)$ & $38(10.4)$ & 0.905 \\
\hline Total & $108(18.3)$ & $72(19.7)$ & 0.585 \\
\hline Medical complications: & & & \\
\hline Cardiovascular & $65(11.0)$ & $57(15.6)$ & 0.046 \\
\hline Pulmonary & $119(20.2)$ & $148(40.5)$ & 0.001 \\
\hline Renal & $15(2.5)$ & $13(3.6)$ & 0.364 \\
\hline Hepatic & $3(0.5)$ & $3(0.8)$ & 0.419 \\
\hline Other & $42(7.1)$ & $28(7.7)$ & 0.750 \\
\hline Total & $191(32.4)$ & $190(52.1)$ & 0.001 \\
\hline Deaths in hospital & $61(10.3)$ & $50(13.7)$ & 0.115 \\
\hline & & & \\
\hline
\end{tabular}


Table 5 Multivariate analysis of risk factors associated with operative mortality and morbidity in oesophagogastric surgery

\begin{tabular}{|c|c|c|c|c|c|c|c|c|}
\hline \multirow[b]{2}{*}{ Risk factor } & \multicolumn{2}{|r|}{ Mortality } & \multicolumn{2}{|c|}{ All complications } & \multicolumn{2}{|c|}{ Medical complications } & \multicolumn{2}{|c|}{ Surgical complications } \\
\hline & $\%$ & OR (95\% Cl) & $\%$ & OR (95\% Cl) & $\%$ & OR $(95 \% \mathrm{Cl})$ & $\%$ & OR $(95 \% \mathrm{Cl})$ \\
\hline \multicolumn{9}{|l|}{ Age (years): } \\
\hline$<60$ & 9.7 & & 48.0 & & 38.3 & & 17.9 & \\
\hline $60-70$ & 9.8 & & 50.4 & & 41.0 & & 20.7 & \\
\hline $71-80$ & 13.6 & & 48.5 & & 41.1 & & 16.6 & \\
\hline$\geq 80$ & 14.1 & & 47.8 & & 37.0 & & 20.7 & \\
\hline \multicolumn{9}{|l|}{ Sex: } \\
\hline Female & 9.9 & & 41.9 & 1 & 36.3 & & 16.9 & \\
\hline Male & 12.3 & & 51.8 & 1.45 (1.07 to 1.99$)$ & 41.7 & & 19.6 & \\
\hline \multicolumn{9}{|c|}{ Possum physiological score: } \\
\hline $11-14$ & 6.5 & 1 & 40.3 & 1 & 29.9 & 1 & 15.9 & \\
\hline $15-20$ & 10.0 & $1.72(0.87$ to 3.37$)$ & 50.1 & 1.51 (1.00 to 2.28$)$ & 42.3 & 1.60 (1.11 to 2.31$)$ & 19.2 & \\
\hline $20-30$ & 18.5 & 4.12 (1.99 to 8.54$)$ & 56.8 & 2.23 (1.28 to 3.91$)$ & 50.6 & 2.60 (1.58 to 4.26$)$ & 19.8 & \\
\hline$>30$ & 24.0 & 6.46 (2.06 to 20.27 ) & 56.0 & 2.55 (0.91 to 7.15$)$ & 48.0 & 2.50 (0.98 to 6.36$)$ & 16.0 & \\
\hline \multicolumn{9}{|l|}{ ECOG status: } \\
\hline 0 & 9.6 & & 47.1 & & 36.5 & & 19.3 & \\
\hline 1 & 10.9 & & 47.3 & & 39.5 & & 17.9 & \\
\hline 2 & 18.9 & & 54.1 & & 46.7 & & 19.7 & \\
\hline $3 / 4$ & 16.7 & & 50.0 & & 50.0 & & 16.7 & \\
\hline \multicolumn{9}{|l|}{ ASA grade: } \\
\hline 1 & 7.8 & & 41.0 & 1 & 31.9 & 1 & 17.5 & \\
\hline II & 9.0 & & 48.3 & 1.23 (0.88 to 1.92$)$ & 38.5 & $1.3(0.90$ to 1.96$)$ & 20.0 & \\
\hline III & 18.2 & & 54.5 & 1.74 (1.09 to 2.78$)$ & 47.5 & $1.6(1.06$ to 2.67$)$ & 18.2 & \\
\hline IV & 27.3 & & 72.7 & $3.20(0.74$ to 13.8$)$ & 72.7 & 4.64 (1.11 to 19.43$)$ & 9.1 & \\
\hline \multicolumn{9}{|l|}{ Surgeon's assessment: } \\
\hline 1 & 7.3 & 1 & 46.2 & & 37.0 & & 19.5 & \\
\hline $2 / 3$ & 19.0 & 2.62 (1.47 to 4.68$)$ & 56.1 & & 49.1 & & 18.2 & \\
\hline \multicolumn{9}{|l|}{ Operative intent: } \\
\hline Curative & 11.6 & & 49.0 & & 40.4 & & 18.8 & \\
\hline Palliative & 11.3 & & 43.5 & & 32.3 & & 19.4 & \\
\hline \multicolumn{9}{|l|}{ Surgical approach: } \\
\hline Abdominal & 10.3 & & 18.2 & 1 & 31.8 & 1 & 18.2 & \\
\hline Thoracic & 12.7 & & 19.2 & 1.57 (1.15 to 2.15$)$ & 48.1 & 2.78 (1.59 to 4.86$)$ & 19.2 & \\
\hline \multicolumn{9}{|l|}{ Additional organ: } \\
\hline Not resected & 11.4 & & 44.7 & 1 & 37.5 & & 16.1 & 1 \\
\hline Resected & 12.5 & & 61.6 & 1.48 (0.99 to 2.21$)$ & 47.8 & & 27.7 & 1.52 (1.06 to 2.20$)$ \\
\hline \multicolumn{9}{|l|}{ Lymphadenectomy: } \\
\hline Non-radical & 10.1 & & 43.0 & 1 & 34.7 & 1 & 14.8 & 1 \\
\hline Radical & 11.9 & & 55.7 & $1.43(0.99$ to 2.05$)$ & 46.2 & 1.46 (1.00 to 2.13$)$ & 22.6 & 1.44 (0.97 to 2.14$)$ \\
\hline \multicolumn{9}{|l|}{ Cancer stage: } \\
\hline Stage I & 8.3 & 1 & 44.3 & & 37.8 & & 14.8 & 1 \\
\hline Stage II & 12.4 & 1.39 (0.63 to 3.06$)$ & 46.4 & & 39.9 & & 17.0 & 1.11 (0.61 to 2.01$)$ \\
\hline Stage III & 11.8 & 1.54 (0.81 to 2.95$)$ & 50.2 & & 41.7 & & 18.5 & 1.25 (0.78 to 1.98$)$ \\
\hline Stage IV & 18.7 & 2.49 (1.03 to 5.98$)$ & 59.3 & & 39.6 & & 35.2 & 2.54 (1.37 to 4.70$)$ \\
\hline \multicolumn{9}{|l|}{ Type of surgery: } \\
\hline Partial gastrectomy & 8.3 & 1 & 36.6 & 1 & 28.1 & 1 & 16.2 & \\
\hline Total gastrectomy & 13.8 & $2.43(1.26$ to 4.70$)$ & 52.0 & 1.90 (1.23 to 2.92$)$ & 39.8 & 1.93 (1.23 to 3.02$)$ & 22.0 & \\
\hline Oesophagectomy & 12.8 & 2.41 (1.27 to 4.56$)$ & 55.8 & 1.17 (0.62 to 2.21$)$ & 28.1 & 1.20 (0.63 to 2.26$)$ & 18.8 & \\
\hline \multicolumn{9}{|l|}{ Annual volume: } \\
\hline $0-10(n=9)$ & 16.7 & 1 & 47.8 & & 35.6 & & 18.9 & \\
\hline $11-20(n=10)$ & 12.7 & $0.50(0.24$ to 1.05$)$ & 44.7 & & 35.0 & & 16.3 & \\
\hline $21-39(\mathrm{n}=4)$ & 10.3 & $0.49(0.24$ to 0.97$)$ & 50.9 & & 43.1 & & 20.2 & \\
\hline Level 2 variance (SE) & & $0.61(0.097)$ & & $0.41(0.22)$ & & $0.78(0.39)$ & & $0.019(0.029)$ \\
\hline
\end{tabular}

mortality, and unit case volumes have been based on systematic literature reviews. ${ }^{9}$ Detailed accurate information is needed to allow appropriate responses both to public scrutiny and to demands for organisational change. We used a large and detailed prospective dataset to determine the factors associated with adverse outcomes for this kind of surgery.

The mortality we report compares unfavourably with that reported in many recent studies, ${ }^{10-12}$ although the contemporary Scottish national audit reported a similar mortality (13\%) for gastrectomy. ${ }^{13}$ The ASCOT contributors were self selected and may therefore be unrepresentative of UK practice overall, but they represent a wide spectrum of large and small, rural and urban, and specialist and generalist departments from England and Wales. The validity of direct comparisons between multicentre cohorts such as ASCOT and some other types of study is doubtful. Mortality in hospital, which we report, is up to $50 \%$ higher than the 30 day mortality reported in many studies. International comparisons are confounded by major differences in populations of patients, and both randomised trials and case series from specialist centres commonly report 
Table 6 Performance of multifactorial models for operative mortality and morbidity

\begin{tabular}{|c|c|c|c|c|}
\hline Model performance & Operative mortality & All complications & Medical complication & Surgical complications \\
\hline \multicolumn{5}{|c|}{ Development set $(n=773)$} \\
\hline Discrimination* (SE) & $0.79(0.03)$ & $0.74(0.02)$ & $0.77(0.02)$ & $0.66(0.03)$ \\
\hline Calibration† & $7.33, P=0.50$ & $3.88, P=0.87$ & $1.23, P=0.99$ & $9.05, P=0.34$ \\
\hline 0:E outcomeł & $12.6 \%: 12.1 \%$ & $49.7 \%: 49.7 \%$ & $40.7 \%: 40.7 \%$ & $20.0 \%: 20.0 \%$ \\
\hline \multicolumn{5}{|l|}{ Test set $(n=222)$} \\
\hline Discrimination* ${ }^{*}(\mathrm{SE})$ & $0.68(0.08)$ & $0.75(0.04)$ & $0.76(0.04)$ & $0.71(0.05)$ \\
\hline Calibration† & $7.39, P=0.49$ & $5.52, P=0.70$ & $8.39, P=0.40$ & 4.63, $P=0.80$ \\
\hline$\overline{0: E \text { outcomeł }}$ & $7.2 \%: 8.8 \%$ & $45.5 \%: 45.5 \%$ & $37.6 \%: 37.0 \%$ & $15.4 \%: 15.3 \%$ \\
\hline
\end{tabular}

*Measured by area under receiver operator characteristic curve: higher values represent better model discrimination.

† Measured by Hosmer Lemeshow statistic ( $8 \mathrm{df}$ ): smaller values represent better model calibration.

fRatio of observed to expected outcome.

superior treatment effects because of selection and publication biases.

\section{Contributing factors}

Factors that may contribute to high operative mortality include a high frequency of unrelated systemic disease, liberal selection criteria for operation, low case volumes in individual units, poor quality or inappropriately radical surgery, and inadequate standards of postoperative care. Occult cardiac disease is higher in the United Kingdom than in many other European countries,${ }^{14}$ and, by international standards, UK surgeons work with limited postoperative nursing and intensive care unit support. ${ }^{15}{ }^{16}$ Patients of surgeons who operate on a high proportion of referred cases have higher mortality, ${ }^{17}$ but the $46 \%$ curative resection rate in this series was not unusually high. Radical lymphadenectomy was not associated with increased mortality in our series, although it was associated with medical and surgical complications.

We found that factors related to patients- the stage and site of the tumour and general health and fitness-were the strongest predictors of postoperative death and complications. The type of resection is determined largely by the site of the tumour, but the exposure used, the extent of node dissection, and, to a lesser extent, excision of additional organs are aspects of the operation over which the surgeon has some control and that independently predicted death or complications. In our study, total gastrectomy was as strongly associated with mortality as oesophagectomy. Only 15 of the participating units performed any oesophagectomies, so this procedure may be more widely recognised as requiring specialist skill and resources. "Medical" complications were predicted by two measures of patient fitness, by sex, and by more extensive surgery, but surgical complications were predicted only by tumour stage and additional organ resection, although radical node dissection came close to independent significance. Thus the robustness of the patient is not a factor in predicting these complications.

High case volumes in specialist cancer surgery units are associated with superior outcomes in other healthcare systems, ${ }^{4} 18$ but evidence about this association in the UK context is limited. The Scottish audit did not find a clear effect of case volume on mortality ${ }^{13}$ while an audit in the South West region found an effect that just achieved significance. ${ }^{20}$ We found a trend in favour of a weak volume effect compatible with the latter study. The presence of an association does not prove causality, and the proposition that increasing average unit case throughput would improve mortality remains unproved. The test set results showed the reliability of the model developed from the first three years of data by their confirmation of the predictive associations noted.

\section{Problems with data collection}

Submission of data to ASCOT was voluntary and essentially unfunded, and, not surprisingly, the completeness of data recording varied considerably. Rates of omission of clinical data were reduced by internal verification work to between $5 \%$ and $10 \%{ }^{21}$ Overall, ASCOT recorded two thirds of the cases recorded by hospital episode statistics, although figures for individual trusts varied considerably. Comparison of mortality data with figures from hospital episode statistics showed no evidence of overall bias, even among trusts who contributed few cases to ASCOT. The uneven quality of the hospital episode statistics data reflected the experience of others. ${ }^{22}$ Large clinical databases are robust and generally produce effect estimates close to the true effect in the face of substantial omissions. ${ }^{23}{ }^{24}$ Multiple databases gave similar results for cardiac surgery outcomes..$^{25}$

Our study was limited in scope to the elucidation of factors associated with death and complications. Systems like ASCOT will permit the development of accurate predictive scoring models and of risk adjusted comparisons of performance between hospitals and surgeons, but for these purposes near complete data will be required. We have shown both the potential value and the problems of large prospective databases as tools for surgical audit and research. Resources should be provided to improve the ability of multidisciplinary teams to record complete, comprehensive, and accurate data on all patients undergoing major surgery for cancer.

The ASCOT project was developed by the membership of the British Oesophago-gastric Cancer Group. We thank all the consultants who contributed patients to the study and the data collection officers for their assistance. Abdullah Jibawi, David Corless, and David Cade of the Surgical Research Group at Leighton Hospital, Crewe, provided and prepared the HES data for external validation of the ASCOT dataset.Consultants at the following trusts registered with the ASCOT study: Addenbrooke's NHS Trust, Cambridge; Aintree University Hospital, Liverpool; Airedale NHS Trust, Keighley, North Yorkshire; Barnet General Hospital, Hertfordshire; Bishop Auckland General Hospital, County Durham; Broomfield Hospital, Chelmsford; Chorley General Hospital, Lancashire; East Cheshire NHS Trust; Macclesfield District General Hospital, Macclesfield; Essex Rivers Healthcare, Colchester General Hospital, Essex; Furness General Hospital, Cumbria; Glenfield Hospital, Leicester; Harrogate District Hospital, Harrogate; Huddersfield Royal Infirmary, Huddersfield; Leicester Royal Infirmary, Leicester; Leighton Hospital, Crewe, Cheshire; Maidstone General Hospital, Maidstone; Morecambe Bay NHS Trust; Royal Lancaster Infirmary, Lancaster; Newham General Hospital, London; Norfolk and Norwich NHS Trust, Norwich; North Staffordshire City General Hospital, Stoke on Trent; Queen Elizabeth Hospital, Birmingham; Royal Bolton Hospital, Bolton; Royal Free Hospital, London; Royal Hull Hospitals NHS Trust, Hull; Ipswich Hospital, Ipswich; Royal Bournemouth Hospital, Bournemouth; Watford General Hospital, Hertfordshire; West Wales General Hospital, Carmarthen.

Contributors: PM set up the ASCOT study, contributed to the study design, data analysis, and interpretation, and is guarantor. He wrote the first draft of the paper and contributed to subsequent revisions. JW contributed to data extraction and analysis and the editing of the drafts of the paper. PPT designed the approach to the statistical analysis of the data and performed it. He was also involved in all stages of drafting and editing the manuscript. 


\section{What is already known on this topic}

Gastro-oesophageal cancer resections carry the highest mortality among elective general surgical procedures, but reported results vary widely between institutions

Units with higher case volumes are associated with better results in some non-UK settings and in an English region with only one high volume centre, but not in Scotland

\section{What this study adds}

In a large sample of English hospitals, morbidity and mortality remain high and are influenced more by the preoperative condition of the patient than by unit volume

Prospective collection of risk adjusted data allows evaluation of the factors affecting operative outcome and requires a multidisciplinary input with adequate resources to ensure complete and accurate data collection

Funding: PPT was funded by the "Hue Falwasser" research fellowship of the Royal College of Surgeons of England. The University Hospital Aintree Trust provided an initial grant to the ASCOT project.

Competing interests: None declared.

Ethical approval: Not needed.

1 Meyer W, Popp M, Klinger L, Awad-Allah A, Gebhardt C. Results of surgical therapy of adenocarcinomas of the esophagogastric junction according to a standardized surgical adenocarcinomas of the esophagogastric junction
resection technique. Dig Surg 2002;19:269-74.

2 Bailey SH, Bull DA, Harpole DH, Rentz JJ, Neumayer LA, Pappas TN, et al. Outcomes after esophagectomy: a ten-year prospective cohort. Ann Thorac Surg 2003;75:217-22.

Sano T, Katai H, Sasako M, Maruyama K. One thousand consecutive gastrectomies without operative mortality. Br J Surg 2002;89:123.

4 McCulloch P, Cummins J. ASCOT: a comprehensive clinical database for gastro-oesophageal cancer surgery. Eur J Surg Oncol 2001;27:709-13.

5 Copeland GP, Jones D, Walters M. POSSUM: a scoring system for surgical audit. $\mathrm{Br} J$ Surg 1991;78:355-60.

6 Oken MM, Creech RH, Rormay DC, Horton J, Davis TE, Mcfadden ET, et al. Toxicity and response criteria of the Eastern Co-operative Oncology Group. Am J Clin Oncol 1982;5:649-55.

7 Vacanti CJ, Van Houten RJ, Hill RC. A statistical analysis of the relationship of physical status to postoperative mortality in 68,388 cases. Anesth Analg 1970;49:564.

8 Harrell FE, Lee KL, Mark DB. Multivariable prognostic models: issues in developing models, evaluating assumptions and adequacy, and measuring and reducing errors Stat Med 1996;15:361-87
9 Clinical Outcomes Group, NHS Executive. Guidance on commissioning cancer services. Improving the outcomes in upper gastro-intestinal cancers: the research evidence. London: Department of Health, 2001.

10 Siewert JR, Bottcher K, Stein HJ, Roder JD for German Gastric Carcinoma Group. Relevant prognostic factors in gastric cancer: ten year results of the German gastric cancer study. Ann Surg 1998;228:449-61.

11 Wanebo HJ, Kennedy BJ, Chmiel J, Steele G Jr, Winchester D, Osteen R. Cancer of the stomach: a patient care study by the American College of Surgeons. Ann Surg 1993;218:583-92.

12 Karl RC, Schreiber R, Boulware D, Baker S, Coppola D. Factors affecting morbidity, mortality, and survival in patients undergoing Ivor Lewis esophagogastrectomy. Ann Surg $2000 \cdot 291: 635-43$

13 Thompson AM, Park KGM for the Scottish Audit of Gastric and Oesophageal Cancer. Does hospital size influence the outcome of patients with gastric cancer undergoing surgery? BrJ Surg 2002;89(S):89.

14 British Heart Foundation. International statistics. www.heartstats.org (accessed 28 March 2003).

15 Crosby DL, Rees GA. Provision of postoperative care in UK hospitals. Ann R Coll Surg Engl 1994;76:14-8.

16 Turner M, McFarlane HJ, Krukowski ZH. Prospective study of high dependency care requirements and provision. JR Coll Surg Edinb 1999;44:19-23.

17 Pye JK, Crumplin MK, Charles J, Kerwat R, Foster ME, Biffin A. One-year survey of carcinoma of the oesophagus and stomach in Wales. BrJ Surg 2001;88:278-85.

18 Begg CB, Cramer LD, Hoskins WJ, Brennan MF. Impact of hospital volume on operative mortality for major cancer surgery. JAMA 1998;280:1747-51.

19 Van Lanschot JJ. Hulscher JB, Buskens CJ, Tilanus HW, ten Kate FJ, Obertop H. Hospital volume and hospital mortality for esophagectomy. Cancer 2001;91:1574-8.

20 Bachmann MO, Alderson D, Edwards D, Wotton S, Bedford C, Peters TJ, et al. Cohort study in South and West England of the influence of specialization on the management and outcome of patients with oesophageal and gastric cancers. BrJ Surg 2002;89:91422.

21 Warsi A, White S, McCulloch P. Completeness of data entry in three cancer surgery databases Eur J Surg Oncol 2002;28:850-6.

22 Spiegelhalter DJ, Aylin P, Best NG, Evans SJW, Murray GD. Commissioned analysis of surgical performance by using routine data: lessons from Bristol inquiry.J $R$ Statist Soc A 2002;165:1-31.

23 Evans WK, Crook J, Read D, Morriss J, Logan DM. Capturing tumour stage in a cancer information database. Cancer Prev Control 1998;2:304-9.

24 Robertsson O, Dunbar M, Knutson K, Lewold S, Lidgren L. Validation of the Swedish knee arthroplasty register: a postal survey regarding 30,376 knees operated on between 1975 and 1995. Acta Orthop Scand 1999;70:467-72.

25 Aylin P, Alves B, Best N, Cook A, Elliott P, Evans SJ, et al. Comparison of UK paediatric cardiac surgical performance by analysis of routinely collected data 1984-96: was Bristol an outlier? Lancet 2001;358:181-7.

(Accepted 19 September 2003)

bmj.com 2003;327:1192

Academic Unit of Surgery, University of Liverpool, University Hospital Aintree, Liverpool L9 7AI

Peter McCulloch reader in surgery

Chorley and South Ribble District General Hospital, Chorley, Lancashire PR7 1PP Jeremy Ward consultant surgeon

Academic Department of Surgery, King's College Hospital, London SE5 9RS

Paris P Tekkis research fellow

Correspondence to: P McCulloch

petermcculloch@aol.com 